\title{
A determination method of compressive design value of dimensional lumber
}

\author{
Yong Zhong ${ }^{1,2}\left(\mathbb{0} \cdot\right.$ Guofang $\mathrm{Wu}^{1,2} \cdot$ Haiqing Ren $^{1,2} \cdot$ Zehui Jiang $^{3}$
}

Received: 10 November 2017 / Accepted: 21 May 2018 / Published online: 15 June 2018

(C) The Japan Wood Research Society 2018

\begin{abstract}
The objective of this study was to develop a determination method of compressive design value of dimensional lumber for its safety design and rational application as a green building material. A total of 1049 full-size $2 \times 4$ samples of Chinese larch (Larix gmelinii) dimensional lumber, including visual grades Ic, IIc, IIIc, and IVc, were tested by static compressive tests. Compression strength parallel to grain (UCS) of different grades were summarized. By the least square method, the fitted parameters and results for UCS were obtained under different probability distribution models (normal, lognormal and 2-P-Weibull) and test data points $(100,75,50,25$, and 15\%). Based on reliability analysis method, relationships between the reliability index and partial factor were investigated under different probability distribution models, fitting data points, load combinations and load ratios. Finally, this study suggested that the lognormal distribution, 25\% data points, load combination of dead load plus residential live load, and load ratio of 1.0 be selected for the determination of compressive design value of Chinese larch dimensional lumber. For Chinese larch dimensional lumber, the compressive design values of grade Ic, IIc, IIIc and IVc were 22.9, 18.3, 14.6 and 13.8 MPa, respectively.
\end{abstract}

Keywords Compressive design value $\cdot$ Dimensional lumber $\cdot$ Full size $\cdot$ Reliability analysis

\section{Introduction}

With the increasing demands on green building, wood or wood composite has became a common construction material owing to its environment friendliness, sustainability. In past 20 years, modern wood structures have been rapidly developed in China, especially for light wood structure [1]. Dimensional lumber as a main material is thus widely used in wood structures, which needs a great deal of import from foreign countries [2]. On the other hand, Chinese government and some research institutions have began to manufacture the dimensional lumber used from China's own tree species $[3,4]$.

Yong Zhong

zhongyong108@163.com

1 Research Institute of Forestry New Technology, Chinese Academy of Forestry, Beijing 100091, China

2 Research Institute of Wood Industry, Chinese Academy of Forestry, Beijing 100091, China

3 International center for bamboo and rattan, Beijing 100091, China
Chinese larch (Larix gmelinii), comprised 55\% of the wooded areas and $75 \%$ of forest stocks in China's frigid temperate zone, is an abundant wood resource and can be used to manufacture fabricate dimensional lumber, glued lumber, and wood-based composites owing to its excellent mechanical properties [5].

To utilize Chinese larch as dimensional lumber and to promote development of Chinese light wood structure, a lot of research works have been conducted [6-15]. The effects of testing methods [6], visual grades [7-10] and dimension size $[11,12]$ on mechanical properties of Chinese larch dimensional lumber were investigated as well as relationships between different mechanical properties. Jiang et al. [13] and Zhao et al. [14] analyzed the characteristic values of strength by nonparametric and parametric methods. The probability distribution of compression strength for different dimension sizes was also investigated with different probability distribution models [15]. However, due to lack of sufficient research on the mechanical properties of Chinese larch dimensional lumber, there is no specified determination method of strength design value which is an important strength index in practical engineering design and should be determined by a reasonable method [16]. 
Hence, for the safety design and rational application of Chinese dimensional lumber as a green building material in building structures, the objective of this study was to develop a determination method of compressive design value for dimensional lumber.

\section{Materials and methods}

\section{Materials}

Larch, collected from the Cuigang and Pangu forest farms of Heilongjiang province, China, was selected as test raw materials. The logs with a diameter range of $160-340 \mathrm{~mm}$ and an average tree age of 35 years were cut into $2 \times 4$ dimensional lumber samples. And the length of each sample was $4000 \mathrm{~mm}$. The main grade reduction defects of Chinese larch dimensional lumber were wood knot, and waney edges and crack, as shown in Fig. 1. According to visual grading specifications in Chinese national code [17], these dimensional lumbers were divided into four different groups of visual grades, i.e., grades Ic, IIc, IIIc, and IVc, which can be equated to grades SS, No. 1, No. 2, and No. 3 in the NLGA standard [18].

The number of samples (NO), mean value (AVG), and coefficient of variation (COV) of density for each grade are shown in Table 1. Before compressive testing, all samples were conditioned at $20{ }^{\circ} \mathrm{C}$ and $65 \%$ relative humidity in a standard room, to arrive at the equilibrium moisture content. The measured average moisture content was $11.3 \%$ with a standard deviation of $1.11 \%$ [19].

\section{Static testing method}

Two specimens with a length of $350 \mathrm{~mm}$ were cut from each sample. One specimen contained the maximum grade reduction defect and another specimen contained the second maximum grade reduction defect according to Chinese national code GB/T 28,993 [20]. The static compressive tests were conducted with a load rate of $1 \mathrm{~mm} / \mathrm{min}$, as shown in Fig. 2 . The UCS of each specimen was calculated as follows:

$\mathrm{UCS}=F_{\max } /(b t)$

where $F_{\max }$ is the maximum load $(\mathrm{N}) ; b$ is the width of specimen (mm); $t$ is the thickness of specimen $(\mathrm{mm})$. At last, smaller UCS of the above two specimens was considered as the final UCS of each sample.

It is well known that the moisture content of structural wood materials will directly affect its test strength value, and will also affect the subsequent determination of compressive design value [21]. Therefore, to unify the test strength value and compressive design value, each country often specifies a moisture content point as the reference point.
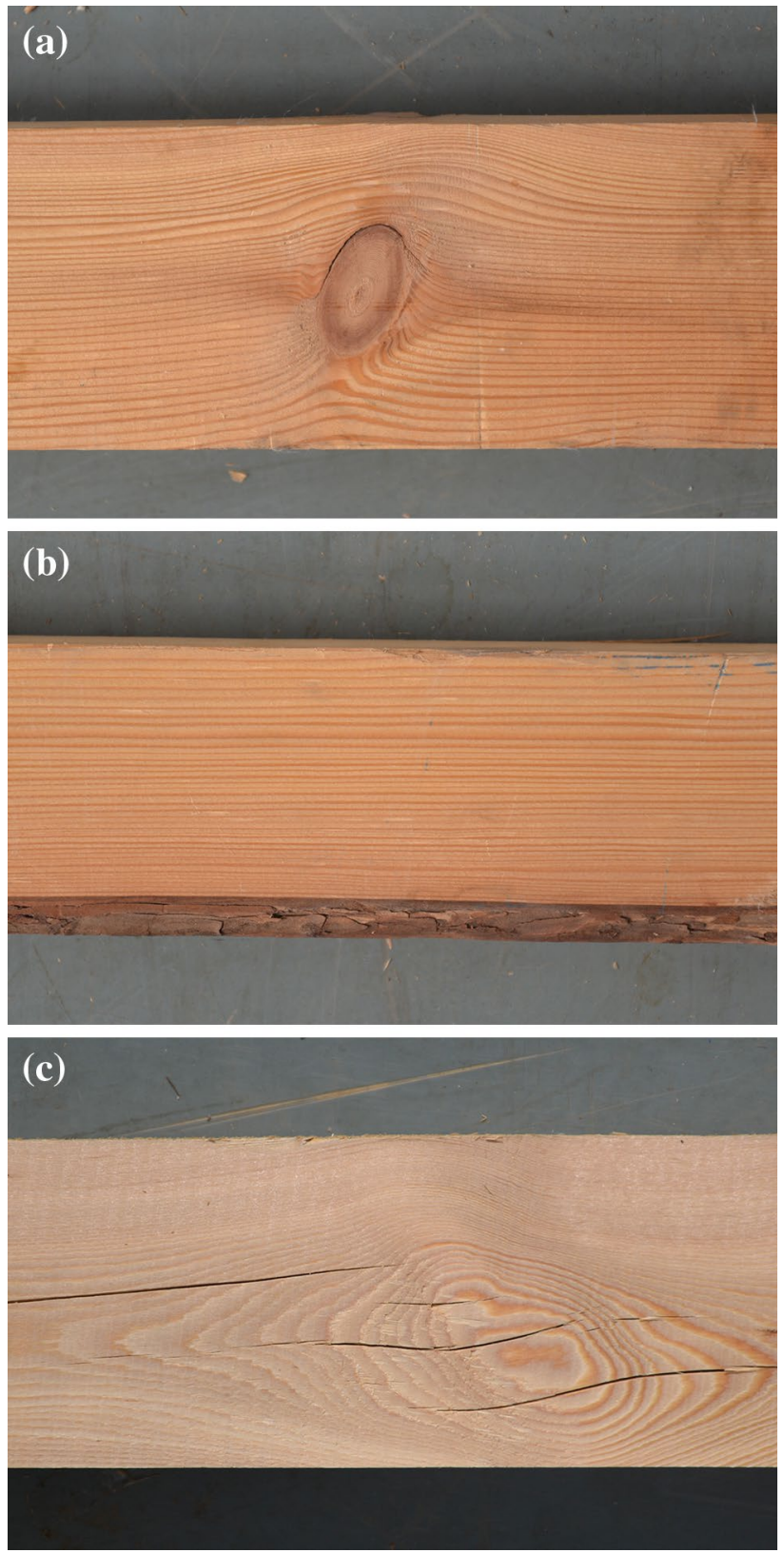

Fig. 1 Main grade reduction defects of Chinese larch dimensional lumber: a wood knot; $\mathbf{b}$ waney edges; $\mathbf{c}$ crack

Table 1 Number of sample and density of each grade dimensional lumber

\begin{tabular}{llll}
\hline Grade & No. & Density & \\
\cline { 3 - 4 } & & AVG $\left(\mathrm{kg} / \mathrm{m}^{3}\right)$ & COV $(\%)$ \\
\hline Ic & 418 & 647 & 10.9 \\
IIc & 207 & 649 & 11.0 \\
IIIc & 274 & 649 & 11.5 \\
IVc & 150 & 658 & 11.0 \\
\hline
\end{tabular}




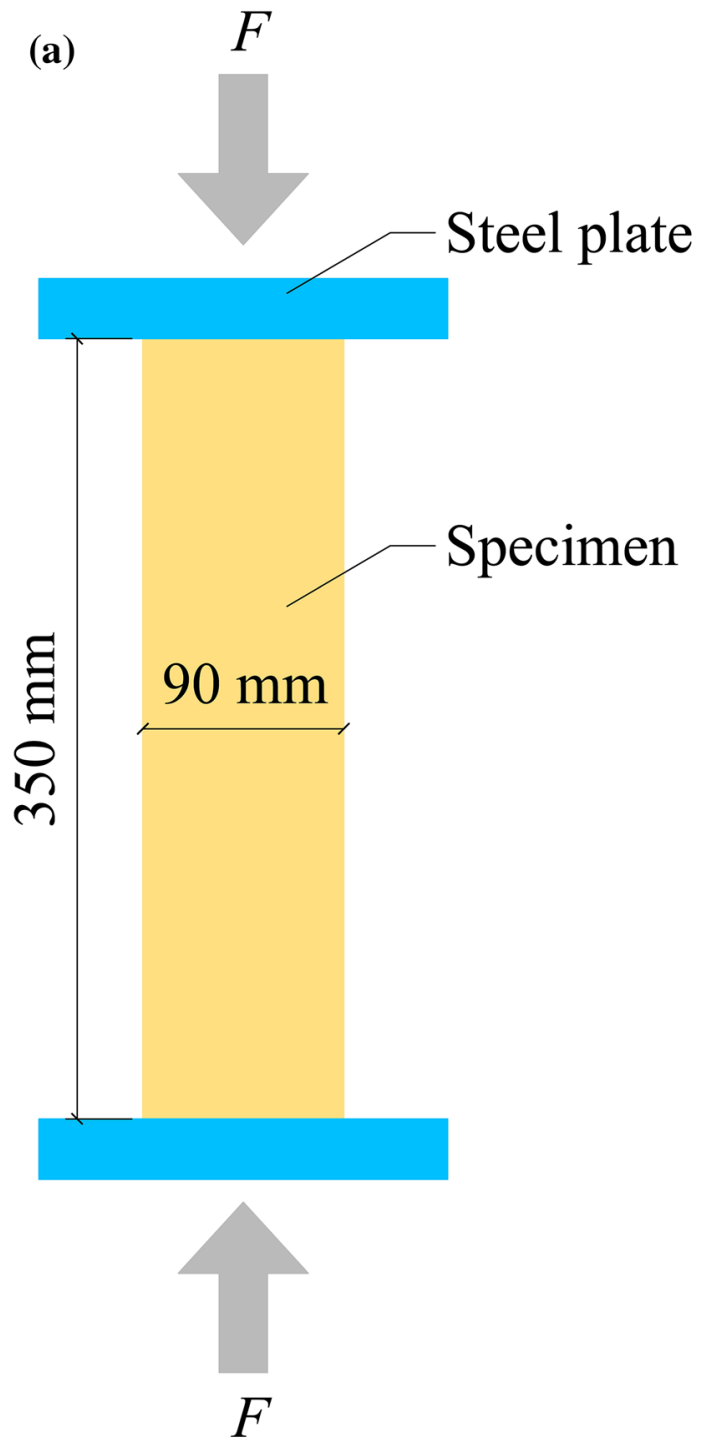

(b)

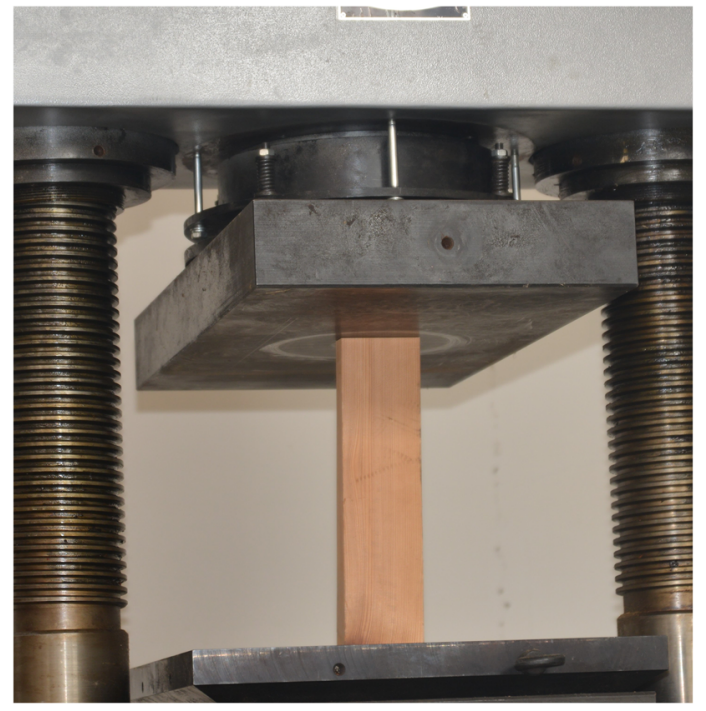

Fig. 2 Static compressive test on specimens: a schematic drawing; b photo
For example, $15 \%$ moisture content was selected as the reference point in United States and Canada [22, 23] while 12\% moisture content in China [17]. According to the specified reference point, the dry moisture content for Chinese larch dimensional lumber was set to $12 \%$, and the actual measured moisture content ranged from 9 to $17 \%$. The UCS of each sample, adjusted to $12 \% \mathrm{MC}\left(\mathrm{UCS}_{12}\right)$ in accordance with ASTM D1990 [24], can be represented as follows:

$\mathrm{UCS}= \begin{cases}\mathrm{UCS} & \mathrm{UCS} \leqslant 9.66 \mathrm{MPa} \\ \mathrm{UCS}+(\mathrm{UCS}-9.66) \times\left(M_{1}-12\right) /\left(34-M_{1}\right) & \mathrm{UCS}>9.66 \mathrm{MPa}\end{cases}$

where $M_{1}$ is the actual measured moisture content of sample $(\%)$.

\section{Statistical analysis}

\section{Probability distribution model}

In timber structure, three types of probability distribution model including normal, lognormal and 2-P-Weibull distribution are common used to fit the probability distribution of test $\mathrm{UCS}_{12}$. The cumulative distribution function $\left(F_{0}(x)\right)$ with different models could be expressed as follows:

Normal: $F_{0}(x)=\frac{1}{\sqrt{2 \pi} \sigma} \int_{-\infty}^{x} e^{-\frac{(t-\mu)^{2}}{2 \sigma^{2}}} \mathrm{~d} t$

Lognormal: $F_{0}(x)=\frac{1}{\sqrt{2 \pi} \sigma} \int_{-\infty}^{x} \frac{1}{t} \mathrm{e}^{-\frac{(\ln (t)-\mu)^{2}}{2 \sigma^{2}}} \mathrm{~d} t$

2-P-Weibull: $F_{0}(x)=1-\mathrm{e}^{-(x / \lambda)^{k}}$

where $x$ is a random variable of $\mathrm{UCS}_{12}$ obtained by static compressive tests; $\mu$ and $\sigma$ are the statistical parameters of mean value and standard deviation; $\lambda$ and $k$ are the scale parameter and shape parameter, respectively. These unknown parameters $\mu, \sigma, \lambda$ and $k$ used in different probability distribution models were determined by the least square method.

Besides, the fitting rear-end probability distribution of $\mathrm{UCS}_{12}$ had a great influence on the calculation of compressive design value, as reported by Foschi et al. [25]. If all test data points $(100 \%)$ were used to fit directly, the rear-end probability of $\mathrm{UCS}_{12}$ fitted by different probability distribution models may differ from the test value. Especially when the test data points are less, this difference between them may be more pronounced [25]. To reduce this difference and to accurately predict the rear-end probability of $\mathrm{UCS}_{12}$, only the first part $(75,50,25$, and $15 \%)$ from all test data 
points which were sorted in ascending order was used to fit, as shown in Fig. 3.

\section{One-way analysis of variance (ANOVA)}

The differences in $\mathrm{UCS}_{12}$ between different grades were analyzed by one-way analysis of variance (ANOVA); multiple comparisons for different grades were calculated by the least significant difference (LSD) method using SPSS 19.0 (IBM SPSS Corporation, Chicago, USA). Significance level was set to 0.05 .

\section{Reliability analysis}

In classical determination method, uncertainties are not considered. However, the resistance and bearing loads are randomness $[16,26]$. In view of reliability analysis concepts, it is important to determine the statistical parameters of random variables and limit states. Random variables give the uncertainty and are defined by described probability distribution model and statistical distribution parameters. Limit state function defines a failure event for determining the corresponding failure probability.

\section{Resistance variables}

For determining the resistance, statistical parameters of short-term compression strength uncertainty are needed first to be investigated and would be determined by following analysis. The statistical parameters of geometric dimension uncertainty, calculation model uncertainty and the uncertainty of long-term load effect are summarized in Table 2 according to Chinese national standards [17].

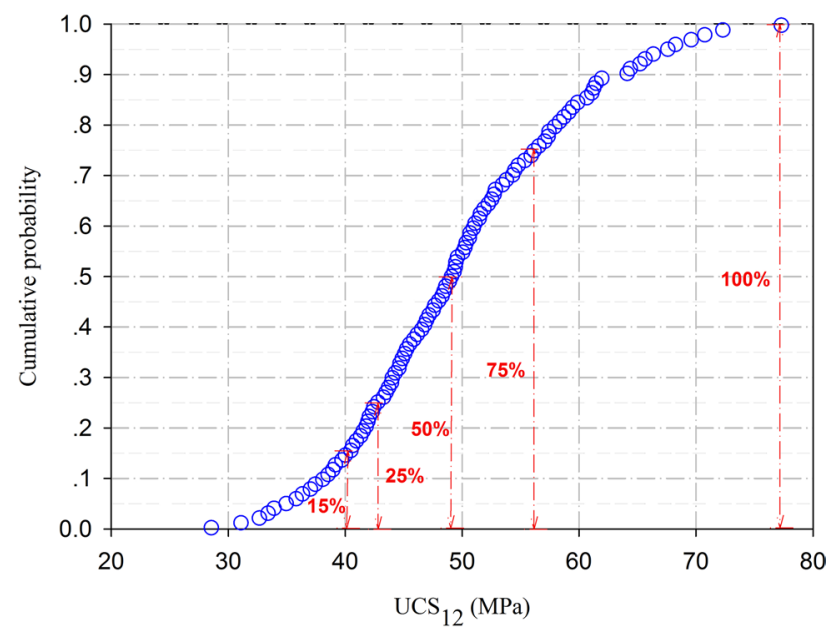

Fig. 3 Fitted by different test data points for three types of probability distribution models
Table 2 Resistance random variables parameters [17]

\begin{tabular}{lllc}
\hline Random variables & Distribution & AVG & COV $(\%)$ \\
\hline Geometric dimensions $\left(K_{\mathrm{A}}\right)$ & Normal & 1.00 & 5 \\
Equation precision of resistance $\left(K_{\mathrm{P}}\right)$ & Normal & 1.00 & 5 \\
Long-term loading effect $\left(K_{\mathrm{Q}}\right)$ & Normal & 0.72 & 12 \\
\hline
\end{tabular}

\section{Load random variables}

As specified by Chinese national standards [17, 27], five types of load including the dead load $(D)$, residential occupancy load $(R)$, official occupancy load $(O)$, snow load $(S)$ and wind load $(W)$ were considered in reliability analysis. Random variables of load are summarized in Table 3, with the probability distribution model and statistical distribution parameters.

\section{Analysis method}

According to reliability design requirements [28, 29], the limit state equation for structural members, i.e., the performance function, could be expressed as follows:

$G=R-(D+L)$

where $R, D$, and $L$ are random variables representing the resistance, dead load $(D)$, and live load $(R, O, W$, or $S)$, respectively.

For dimensional lumber as a compression member [16], the performance function could be converted to Eq. 7, as follows:

$G=f_{\mathrm{s}} K_{\mathrm{A}} K_{\mathrm{P}} K_{\mathrm{Q}}-\frac{f_{\mathrm{k}} k_{\mathrm{D}}(d+\rho l) K_{\mathrm{B}}}{\gamma_{\mathrm{R}}\left(\gamma_{\mathrm{D}}+\rho \psi \gamma_{\mathrm{L}}\right)}$

where $f_{\mathrm{s}}$ is a random variable and represents the short-term $\mathrm{UCS}_{12}$ whose AVG and COV with different probability distribution models would be determined by the least square method; $K_{\mathrm{A}}, K_{\mathrm{P}}, K_{\mathrm{Q}}$ and $K_{\mathrm{B}}$ are also random variables, their statistical parameters in Tables 2 and $3 ; d, l$ are random

Table 3 Load random variables parameters [17, 27]

\begin{tabular}{llll}
\hline Random variables & Distribution & Nominal AVG & Cov (\%) \\
\hline $\begin{array}{l}\text { Dead load }(D) \\
\text { Residential occupancy load } \\
(R)\end{array}$ & Normal & 1.06 & 7 \\
Official occupancy load $(O)$ & Extreme-I & 0.644 & 23.3 \\
Snow load $(S)$ & Extreme-I & 1.04 & 28.8 \\
Wind load $(W)$ & Extreme-I & 1.00 & 22 \\
$\begin{array}{l}\text { Uncertainty of the load effect } \\
\left(K_{\mathrm{B}}\right)\end{array}$ & Normal & 1.00 & 5 \\
\hline
\end{tabular}


variables and represent the nominal dead load $\left(D / D_{\mathrm{K}}\right)$ and live load $\left(L / L_{\mathrm{K}}\right)$, their statistical parameters in Table $3 ; K_{\mathrm{D}}$ is a constant value for the adjust factor of long-term load and is equal to the mean value of random variable $K_{\mathrm{Q}} ; f_{\mathrm{k}}$ is the characteristic value of $\mathrm{UCS}_{12}$ and is a constant value; $\rho$ is the ratio of characteristic value of live load to that of dead load $\left(L_{\mathrm{K}} / D_{\mathrm{K}}\right)$ and is a constant variable; $\gamma_{\mathrm{D}}$ and $\gamma_{\mathrm{L}}$ are the partial factor for dead load and live load, and are constant value; $\Psi$ is the load combination factor and is a constant value.

In reliability analysis, four types of load combination were considered, including constant load plus residential occupancy live load $(D+R)$, constant load plus official occupancy live load $(D+O)$, constant load plus snow live load $(D+S)$, and constant load plus wind live load $(D+W)$. And seven kinds of load ratio were considered, including $\rho=0$, $0.25,0.5,1.0,2.0,3.0,4.0$, where $\rho=0$, said the constant load acting alone. The values of $\gamma_{\mathrm{D}}, \gamma_{\mathrm{L}}$ and $\Psi$ were specified in Chinese national standard GB 50,009-2012 [27]. The structural safety level was specified as grade two and the design life was specified as 50 years. Therefore, the target reliability $\beta_{0}$ should be 3.2 for compression test where a ductile failure happened.

The first-order second-moment method was used and performed for all data cells and simulation load cases in reliability analysis, and its calculation program was compiled based on the Matlab 7 software (MathWorks Corporation, Massachusetts Natick, USA). The effects of the fitting data points, probability distribution model, load combination and load ratio on the reliability index $(\beta)$ were investigated.

\section{Results and discussion}

\section{Results of static compressive test}

The statistical parameters of the adjusted compression strength $\left(\mathrm{UCS}_{12}\right)$ of each grade dimensional lumber calculated by Eq. 2 are shown in Table 4, including the number of samples (NO), mean value (AVG), and coefficient of variation (COV). It could be found that the adjusted value $\left(\mathrm{UCS}_{12}\right)$ is slightly lower than the un-adjusted value (UCS), and there was no significant difference between them.

Table 4 Statistical parameters of compression strength for different grades

\begin{tabular}{|c|c|c|c|c|c|}
\hline \multirow[t]{2}{*}{ Grade } & \multirow[t]{2}{*}{ No. } & \multicolumn{2}{|c|}{ Un-adjusted value (UCS) } & \multicolumn{2}{|c|}{ Adjusted value $\left(\mathrm{UCS}_{12}\right)$} \\
\hline & & AVG (MPa) & $\operatorname{COV}(\%)$ & AVG (MPa) & $\operatorname{COV}(\%)$ \\
\hline Ic & 418 & $49.555 \mathrm{a}$ & 19.5 & $49.841 \mathrm{a}$ & 19.3 \\
\hline IIc & 207 & $38.282 b$ & 17.0 & $38.386 b$ & 17.1 \\
\hline IIIc & 274 & $41.401 \mathrm{~b}$ & 24.8 & $40.956 b$ & 24.7 \\
\hline IVc & 150 & $39.608 b$ & 28.8 & $39.000 \mathrm{~b}$ & 28.5 \\
\hline
\end{tabular}

Furthermore, the $\mathrm{UCS}_{12}$ AVG comparisons between different grades are also shown in Table 4 by one-way anova method. Results indicated that the $\mathrm{UCS}_{12}$ AVG of grade Ic was significantly higher than that of grades IIc, IIIc and IVc $(p<0.01)$; however, there was no significant difference between the UCS ${ }_{12}$ AVG of grades IIc, IIIc and IVc $(p>0.05)$. This was mainly due to the fact that the main grade reduction defect for grade IIc was wood knot, accounts for $90 \%$, while that for grades IIIc and IVc was wood knot, crack or waney edges, each account for about $20-30 \%$. And from the actual compression test, the wood knot could lead to a significant reduction in strength; however the crack and waney edges had less effect on strength. Because of the crack and waney edges, these pieces of dimensional lumber were downgraded to grade IIIc or IVc which may have a higher strength than grade IIc. The similar results also were reported for Tsuga Canadensis [14].

In practical engineering design, all structural materials, including dimensional lumber, should follow the principle that the strength design value of high grade should not be lower than that of low grade [17]. In view of the fact that the $\mathrm{UCS}_{12}$ AVG of grade IIc was slight lower than that of grade IIIc and IVc (Table 4), it was necessary to modify the UCS 12 data of grades IIc, IIIc and IVc if the final determined compressive design value was contrary to this principle requirement. And it is well known that in reliability analysis, the determined strength design value depends not only on the mean value, but also on the coefficient of variation, rear-end probability distribution, and so on $[16,26]$. Therefore, the $\mathrm{UCS}_{12}$ data were not modified at last, because the coefficient of variation of $\mathrm{UCS}_{12}$ was significantly increased with the grade from IIc to IVc, 17.1, 24.7 and 28.5\% (Table 4), respectively.

\section{Probability distribution}

Histograms of $\mathrm{UCS}_{12}$ of each grade are shown in Fig. 4. The unknown parameters $\mu$ and $\sigma$ used in normal, lognormal and 2-P-Weibull distribution models (Eqs. 3-5) were determined by the least square method. The fitting results are shown in Table 5. Based on the fitting parameters, the predicted and actual test cumulative probability distribution curves were plotted. To compare the differences between the predicted and actual test cumulative probability, the curves of grade Ic was given as an illustrative example, as shown in Fig. 5.

From Fig. 5, it could be found that the fitting data points and probability distribution model had significant effects on the fitting results. For grade Ic, when $100 \%$ test data points were used to fit, the $\mathrm{UCS}_{12}$ at the rear-end probability $(P<0.2)$ fitted by normal and $2-P-W e i b u l l$ probability distribution was lower than that the test value, while that fitted by lognormal probability distribution was close to the test value. With the decrease of fitting data points from 100 

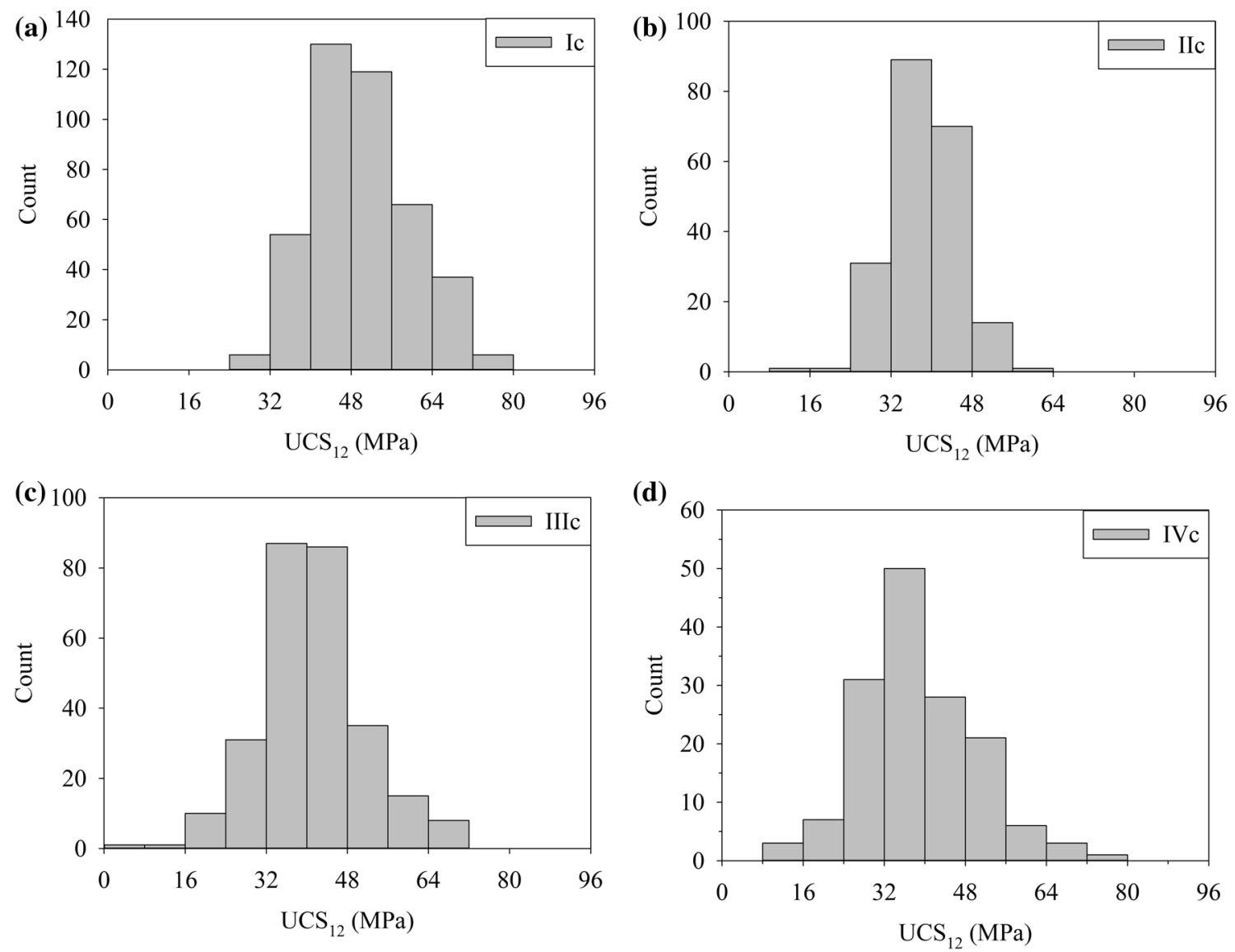

Fig. 4 Histograms of UCS He $_{12}$ of different grades: a Ic; b IIc; $\mathbf{c}$ IIIc; d IVc

Table 5 Characteristic values and fitting results of $\mathrm{UCS}_{12}$ of different grades

\begin{tabular}{|c|c|c|c|c|c|c|c|c|c|c|c|c|}
\hline \multirow[t]{2}{*}{ Grades } & \multirow[t]{2}{*}{$f_{\mathrm{k}} / \mathrm{MPa}$} & \multirow[t]{2}{*}{ Model } & \multicolumn{5}{|c|}{ Fitting AVG/MPa } & \multicolumn{5}{|c|}{ Fitting COV/\% } \\
\hline & & & $100 \%$ & $75 \%$ & $50 \%$ & $25 \%$ & $15 \%$ & $100 \%$ & $75 \%$ & $50 \%$ & $25 \%$ & $15 \%$ \\
\hline \multirow[t]{3}{*}{ Ic } & \multirow[t]{3}{*}{34.4} & Normal & 49.2 & 49.0 & 48.8 & 48.1 & 48.8 & 19.5 & 18.4 & 17.6 & 16.2 & 17.0 \\
\hline & & Lognormal & 49.9 & 49.8 & 50.0 & 50.2 & 52.2 & 19.8 & 19.5 & 20.0 & 20.2 & 22.8 \\
\hline & & 2-P-Weibull & 48.8 & 48.5 & 48.0 & 46.6 & 46.9 & 20.0 & 18.1 & 16.4 & 13.5 & 13.9 \\
\hline \multirow[t]{3}{*}{ IIc } & \multirow[t]{3}{*}{26.3} & Normal & 38.3 & 38.3 & 38.2 & 38.3 & 39.9 & 16.5 & 16.8 & 16.4 & 16.2 & 18.6 \\
\hline & & Lognormal & 38.6 & 38.8 & 39.0 & 39.9 & 43.7 & 16.7 & 17.7 & 18.4 & 20.0 & 26.2 \\
\hline & & 2-P-Weibull & 37.9 & 37.9 & 37.6 & 37.1 & 38.2 & 16.8 & 16.5 & 15.2 & 13.5 & 15.2 \\
\hline \multirow[t]{3}{*}{ IIIc } & \multirow[t]{3}{*}{23.1} & Normal & 40.5 & 40.5 & 40.4 & 41.9 & 42.2 & 22.7 & 22.1 & 21.7 & 24.3 & 24.7 \\
\hline & & Lognormal & 41.3 & 41.4 & 41.9 & 46.8 & 50.5 & 23.2 & 23.7 & 25.4 & 34.6 & 39.7 \\
\hline & & 2-P-Weibull & 40.2 & 40.1 & 39.7 & 40.9 & 41.1 & 22.8 & 21.6 & 20.2 & 22.0 & 22.4 \\
\hline \multirow[t]{3}{*}{ IVc } & \multirow[t]{3}{*}{22.0} & Normal & 38.2 & 37.8 & 37.2 & 37.7 & 42.0 & 27.7 & 25.6 & 22.5 & 23.2 & 28.4 \\
\hline & & Lognormal & 39.1 & 39.0 & 38.8 & 41.7 & 54.1 & 28.1 & 27.6 & 26.5 & 32.5 & 49.5 \\
\hline & & 2-P-Weibull & 38.0 & 37.6 & 36.7 & 36.7 & 41.9 & 27.8 & 25.4 & 21.1 & 20.7 & 27.3 \\
\hline
\end{tabular}

$f_{\mathrm{k}}$ represents the characteristic value of $\mathrm{UCS}_{12}$; AVG represents the mean value of $\mathrm{UCS}_{12}$; $\mathrm{COV}$ represents the coefficient of variation of $\mathrm{UCS}_{12}$ to $15 \%$, the $\mathrm{UCS}_{12}$ of grade Ic at the rear-end probability fitted by different distribution models began to be the same. Besides, the fitting results indicated that the fitting AVG and COV with $15 \%$ data points for grade IVc were $54.1 \mathrm{MPa}$ and $49.5 \%$, and were seriously deviated from the test value (Table 5).

For all conditions with different fitting data points, the fitting results (Fig. 5) also indicated that the $\mathrm{UCS}_{12}$ fitted 

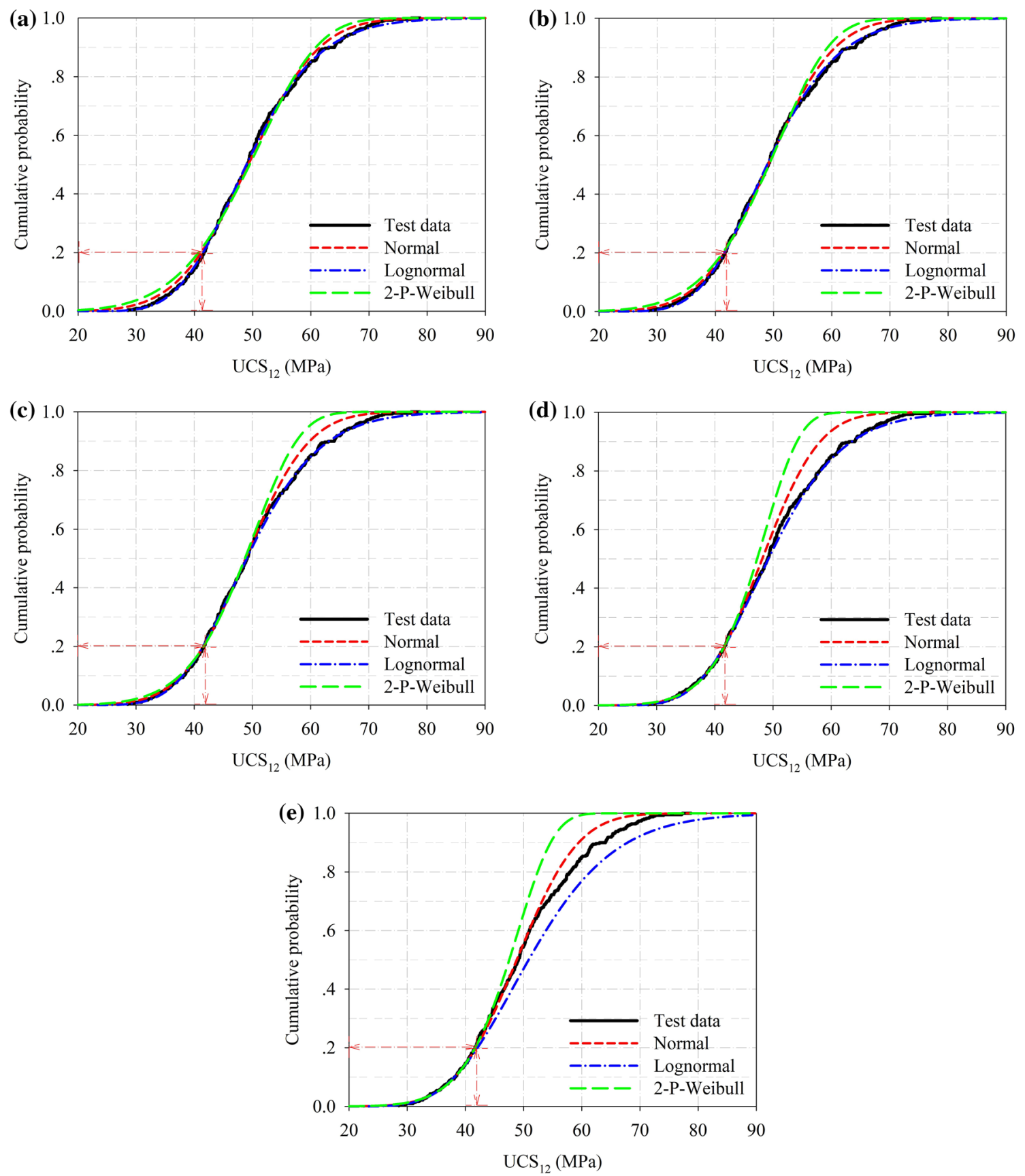

Fig. 5 Fitting results of $\mathrm{UCS}_{12}$ of grade Ic with different fitting data points: a $100 \%$ test data points; b $75 \%$ test data points; c $50 \%$ test data points; $\mathbf{d} 25 \%$ test data points; e $15 \%$ test data points

by lognormal probability distribution was higher than that by normal and 2-P-Weibull probability distribution, especially at the rear-end probability $(P<0.2)$ and the front-end probability $(0.8<P<1.0)$. This could lead to the following calculated partial factor $\left(\gamma_{R}\right)$ by lognormal probability distribution was higher than that by normal and 2-P-Weibull probability distribution, when at the same target reliability index $\left(\beta_{0}=3.2\right)$.
The strength characteristic value is an important strength index, which reflects the characteristics of structural material itself $[13,16]$ and can be used to mark the strength level of material. For structural wood materials, the strength value corresponding to the $5 \%$ quantile value at $75 \%$ confidence is generally defined as the strength characteristic value [13, $16,30]$. The method used to determine the strength characteristic value mainly includes parametric and nonparametric 
method. For dimensional lumber produced by China itself, due to lack of sufficient basic data, there may be a large difference between the predicted probability value and the test value, especially in the rear-end probability section (Fig. 5), when using the parameter method (normal, lognormal or 2-P-Weibull) to infer its strength characteristic value. These factors may eventually lead to a large deviation between the predicted strength characteristic value and the true value. Therefore, in this study, the characteristic values of compression strength of Chinese larch dimensional lumber were determined by nonparametric method which was specified according to ASTM 2915-09 [30]. Based on the total number of samples of each grade dimensional lumber (Table 1), the order of tested data point which was used to determine the characteristic values of compression strength should be 18th for grades Ic, 8th for grade IIc, 11 th for grade IIIc, and 6th for grade IVc, and the corresponding strength of the order of tested data point was 34.3 MPa for grades Ic, 26.3 MPa for grade IIc, 23.1 MPa for grade IIIc, and 22.0 MPa for grade IVc, respectively (Table 5).

\section{Influencing factors of reliability index}

\section{The fitting data points and probability distribution model}

The relationships between the reliability index $(\beta)$ and resistance partial factor $\left(\gamma_{\mathrm{R}}\right)$ under different fitting data points and probability distribution models were similar for each grade dimensional lumber. Therefore, to investigate the effects of fitting data points and probability distribution models on the reliability index, relationship curves of $\beta-\gamma_{R}$ of grade Ic under the load combination of $D+R$ at the load ratio of 1.0 was given as an illustrative example, as shown in Fig. 6.

It can be seen from Fig. 6 that when at the same resistance partial factor, the reliability index obtained by lognormal distribution is the largest, followed by normal distribution and 2-P-Weibull distribution is the smallest. This difference was most obvious when the fitting AVG and COV with $100 \%$ test data points (Table 5) were selected for reliability analysis, as shown in Fig. 6a. This was mainly due to that the $\mathrm{UCS}_{12}$ at the rear-end probability fitted by normal and 2-P-Weibull distribution is significantly lower than the test value, and that fitted by lognormal distribution is closer to the test value (Fig. 5a). However, with the reduction of fitting data points from 100 to $15 \%$, the reliability indexes calculated by different probability distributions began to converge. In the case of reliability analysis using $25 \%$ or $15 \%$ test data points (Fig. $6 \mathrm{~d}$, e), when the reliability index $\beta$ was less than the target reliability index $\left(\beta_{0}=3.2\right)$, the reliability indexes calculated by three different probability distributions were basically the same. This was mainly attributed to that the $\mathrm{UCS}_{12}$ at the rear-end probability fitted by different probability distributions began to be consistent (Fig. 5d, e).
Which kind of fitting data points and probability distribution model should be adopted for determining the compressive design value of dimensional lumber? In Canadian national code [25], the reliability analysis results indicated that the reliability indexes calculated by three different probability distributions using $15 \%$ test data points were basically the same, when the reliability index $\beta$ was less than the target reliability index. Finally, the 2-P-Weibull distribution and $15 \%$ test data points were selected for determining the strength design value of dimensional lumber. However, the determination method of strength design value used in each country is different due to different national circumstances $[16,31]$.

For China, due to the fact that China has only begun to carry out the full-size test for Chinese dimensional lumber in last 15 years, the accumulated data are relatively small. This may lead to a big difference between the predicted probability value and the actual test value, which could directly affect the final determined reliability index and design value. Furthermore, compressive test for dimensional lumber belongs to ductile failure, and the corresponding target reliability index $\left(\beta_{0}\right)$ for this is thus specified to 3.2 according to Chinese national standard $[28,29]$. When using $25 \%$ or $15 \%$ test data points, the reliability indexes calculated by three probability distributions are basically the same (Fig. 6d, e). However, the fitting AVG and COV with 15\% test data points for grade IVc Chinese larch dimensional lumber seriously deviate from the test value, as shown in Table 5. Therefore, considering the economic rationality and the experience accumulated by predecessors, it was finally suggested that the lognormal distribution and $25 \%$ test data points be selected for determining the compressive design value of Chinese larch dimensional lumber.

\section{The load combination and load ratio}

According to the above analysis, the lognormal distribution and $25 \%$ test data points were selected for reliability analysis, and were used to investigate the relationships between the reliability index $(\beta)$ and resistance partial factor $\left(\gamma_{\mathrm{R}}\right)$ under different load combinations $(D+R, D+L, D+S$, $D+W)$ and load ratios $(\rho=0.0,0.25,0.5,1.0,2.0,3.0,4.0)$. Because the laws of $\beta-\gamma_{R}$ curves were similar for each grade, the grade Ic dimensional lumber was given as an illustrative example, as shown in Fig. 7.

It could be seen from Fig. 7 that when at the same resistance partial factor, the reliability index non-linearly increased with the increase of load ratio for the case of $D+R$ and $D+O$ load combinations, however, the reliability index changes little for the $D+S$ and $D+W$ load combinations, which was mainly affected by the statistical value of the live load and constant load [16]. 

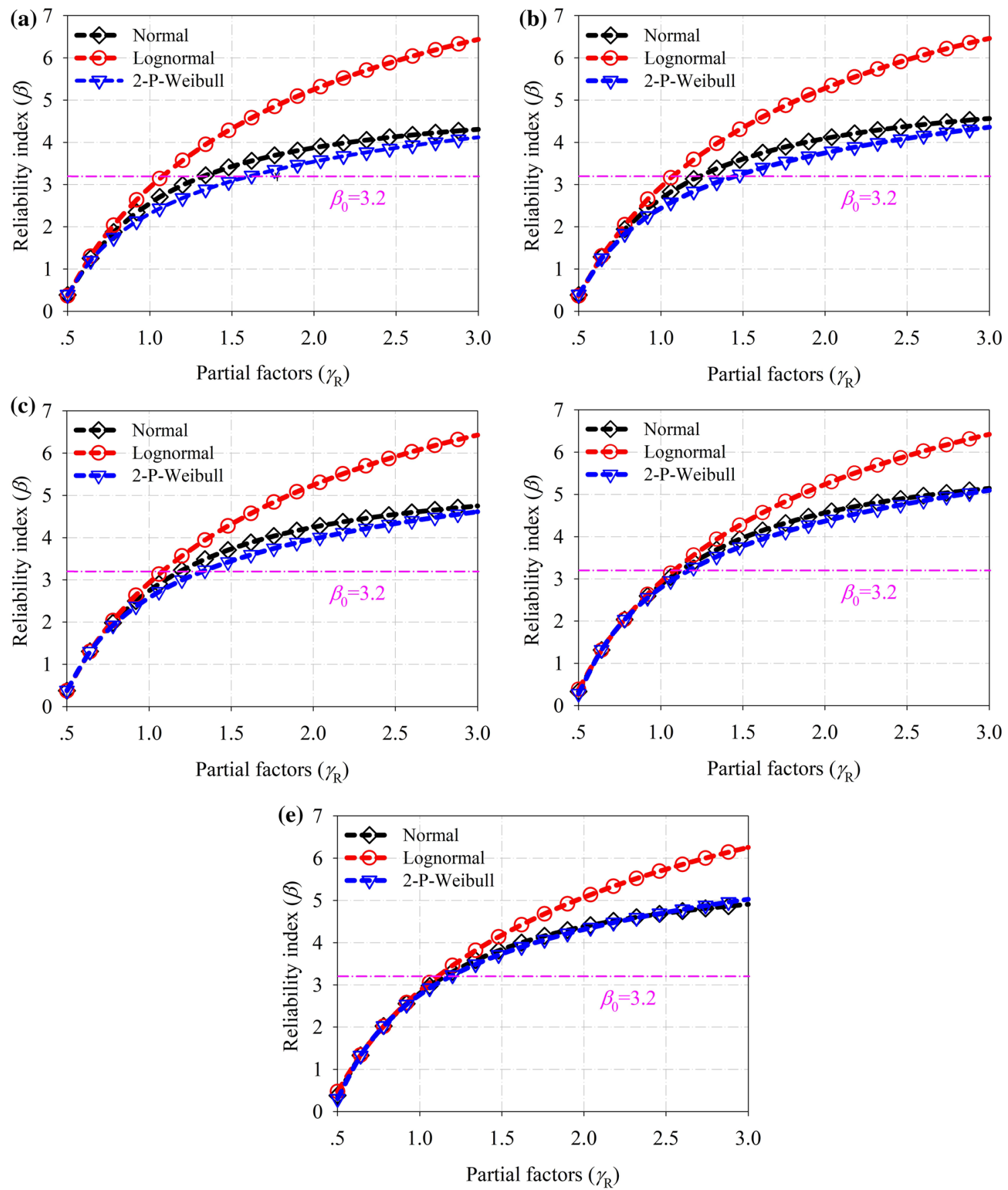

Fig. 6 The $\beta-\gamma_{\mathrm{R}}$ relation of grade Ic dimensional lumber under the load combination $D+R$ and the load ratio $\rho=1.0$ with different type distributions and different fitting data points: a $100 \%$ test data points;

Table 6 shows the corresponding resistance partial factor when the calculated reliability index arrived at the specified target reliability index $\left(\beta_{0}=3.2\right)$. For different grades of dimensional lumber, there were similar results for the resistance partial factor under different load combinations. When the load ratio was less than 0.25 , i.e., the load combination was controlled by the dead load $(D)$, the resistance partial b $75 \%$ test data points; c $50 \%$ test data points; d 25\% test data points; e $15 \%$ test data points

factor under the $D+W$ load combination was the largest, and that under the $D+O$ load combination was the smallest. While when the load ratio was more than 0.25 , i.e., the load combination was controlled by the live load, the resistance partial factor under the $D+S$ load combination was the largest, and that under the $D+O$ load combination was still the smallest. 

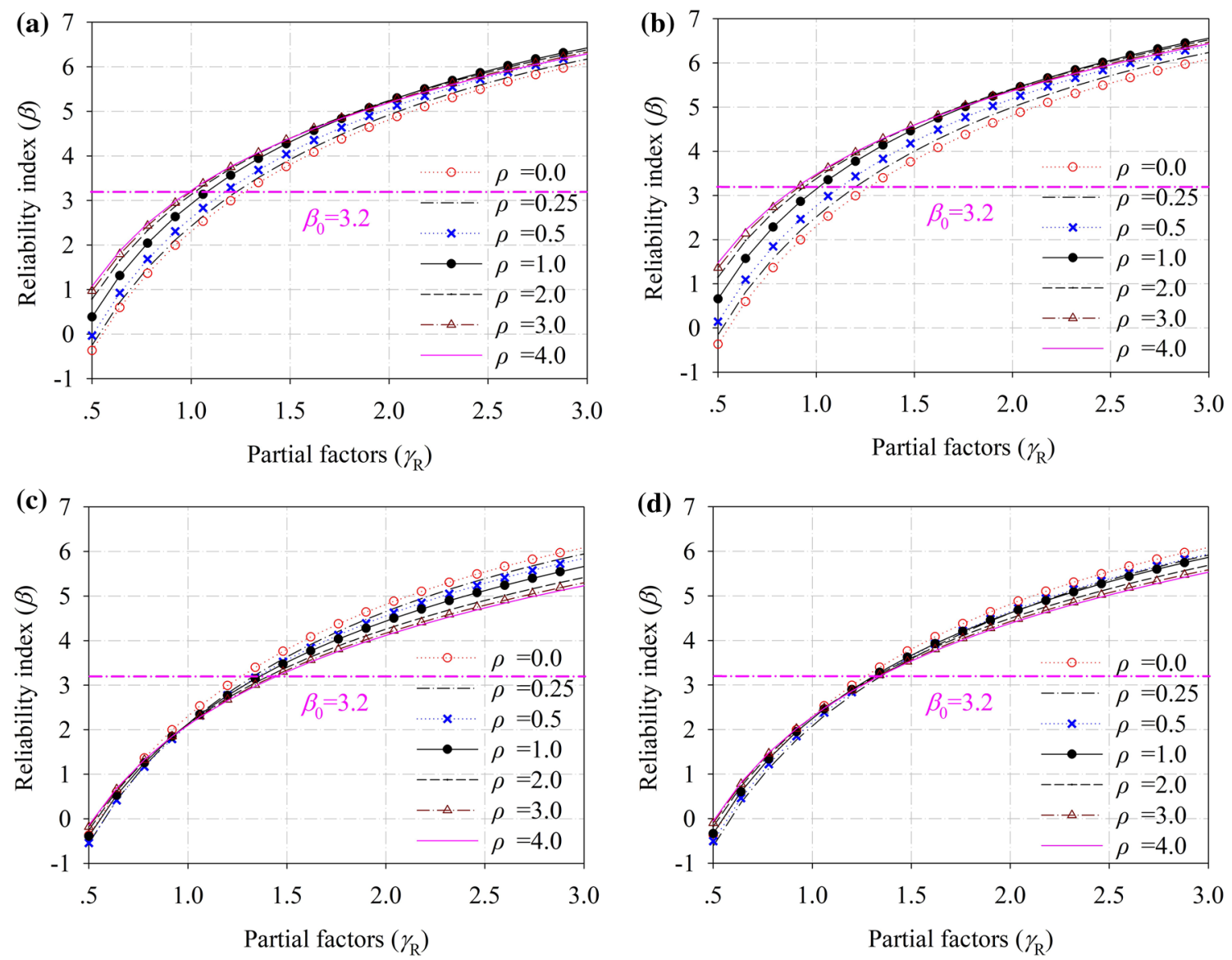

Fig. 7 The $\beta-\gamma_{\mathrm{R}}$ relation of grade Ic dimensional lumber under different load combinations and load ratios: a $D+R ; \mathbf{b} D+O ; \mathbf{c} D+S ; \mathbf{d} D+W$

Table 6 Partial factors for different grades of dimensional lumber under different load combinations and ratios

\begin{tabular}{lllllllll}
\hline Grade & Load combination & \multicolumn{2}{l}{ Load ratios } \\
\cline { 3 - 9 } & & 0.0 & 0.25 & 0.5 & 1.0 & 2.0 & 3.0 & 4.0 \\
\hline Ic & $D+R$ & 1.270 & 1.228 & 1.172 & 1.080 & 1.018 & 1.000 & 0.990 \\
& $D+O$ & 1.270 & 1.200 & 1.124 & 1.014 & 0.940 & 0.914 & 0.902 \\
& $D+S$ & 1.270 & 1.330 & 1.352 & 1.364 & 1.404 & 1.430 & 1.446 \\
& $D+W$ & 1.270 & 1.346 & 1.324 & 1.308 & 1.318 & 1.330 & 1.340 \\
IIc & $D+R$ & 1.216 & 1.176 & 1.122 & 1.034 & 0.976 & 0.956 & 0.948 \\
& $D+O$ & 1.216 & 1.150 & 1.076 & 0.970 & 0.900 & 0.876 & 0.864 \\
& $D+S$ & 1.216 & 1.274 & 1.294 & 1.306 & 1.344 & 1.370 & 1.386 \\
& $D+W$ & 1.216 & 1.290 & 1.268 & 1.252 & 1.262 & 1.274 & 1.282 \\
IIIc & $D+R$ & 1.356 & 1.314 & 1.250 & 1.140 & 1.054 & 1.020 & 1.002 \\
& $D+O$ & 1.356 & 1.284 & 1.198 & 1.066 & 0.962 & 0.924 & 0.902 \\
& $D+S$ & 1.356 & 1.420 & 1.436 & 1.424 & 1.436 & 1.448 & 1.458 \\
& $D+W$ & 1.356 & 1.440 & 1.410 & 1.378 & 1.366 & 1.366 & 1.368 \\
IVc & $D+R$ & 1.366 & 1.324 & 1.258 & 1.148 & 1.064 & 1.032 & 1.014 \\
& $D+O$ & 1.366 & 1.292 & 1.206 & 1.076 & 0.974 & 0.934 & 0.916 \\
& $D+S$ & 1.366 & 1.430 & 1.446 & 1.438 & 1.452 & 1.466 & 1.478 \\
& $D+W$ & 1.366 & 1.450 & 1.420 & 1.390 & 1.380 & 1.380 & 1.384 \\
\hline
\end{tabular}


Table 7 Compressive design value for different grades of dimensional lumber

\begin{tabular}{lllll}
\hline $\begin{array}{l}\text { Tree species of dimensional } \\
\text { lumber }\end{array}$ & \multicolumn{4}{l}{$f_{\mathrm{d}} / \mathrm{MPa}$} \\
\cline { 2 - 5 } & Ic & IIc & IIIc & IVc \\
\hline Chinese larch & 22.943 & 18.294 & 14.577 & 13.769 \\
Spruce-Pine-Fir (SPF) & 17.25 & 13.8 & 13.8 & 8.05 \\
\hline
\end{tabular}

Besides, it could be seen from Table 6 that the resistance partial factor increased gradually from IIc to IVc at the same load combination and load ratio except for grade Ic, which was consistent with the coefficient of variation of different grades of dimensional lumber (COV: IIc $<$ Ic $<$ IIIc $<$ IVc) shown in Table 4 . The higher the coefficient of variation was, the greater the resistance partial factor was.

\section{Design value of compression strength}

According to the target reliability requirement by limit state design method, the design value of structural wood materials could be calculated as $[16,17]$ :

$f_{\mathrm{d}}=f_{\mathrm{k}} K_{\mathrm{D}} / \gamma_{\mathrm{R}}$

where $f_{\mathrm{d}}$ is the compressive design value; $f_{\mathrm{k}}$ is the characteristic value of $\mathrm{UCS}_{12}$ (Table 5); $K_{\mathrm{D}}$ is the adjust factor for long loading effect and is specified to be 0.72 based on Chinese national standard GB 50,005-2003 [17]; $\gamma_{\mathrm{R}}$ is the resistance partial factor shown in Table 6.

The compressive design value should be a fixed value for each grade dimensional lumber. Therefore, it should be first determined which kind of load combination and load ratio to choose for determining the compressive design value. From the above analysis results in Table 6, it was the most conservative method that the load combination of $D+R$ was selected when the load ratio was no greater than 0.25 while the load combination of $D+S$ was selected when the load ratio was more than 0.25 . But this method is too conservative to make full use of material and is lack of economic rationality. Therefore, it was finally suggested that the load combination of $D+R$ and the load ratio of 1.0 be selected to determine the compressive design value for Chinese dimensional lumber, just as mentioned by Zhu et al. [16].

According to the above determination method, the compressive design value of each grade was calculated by Eq. 8 . Compared with common imported $2 \times 4$ SprucePine-Fir (SPF) dimensional lumber for China, the compressive design value of Chinese larch dimensional lumber was higher for each grade, as shown in Table 7. Furthermore, the final determined compressive design values of grade Ic, IIc, IIIc, IVc of $2 \times 4$ dimensional lumber were 22.9, 18.3, 14.6 and $13.8 \mathrm{MPa}$, and met the principle requirements that the strength design value of the high grade should not be lower than the low grade [17].

\section{Conclusions}

To utilize the Chinese larch as dimensional lumber and to promote the development of Chinese light wood structure, a determination method of compressive design value for dimensional lumber was developed. Based on the analysis results, this study suggested that the lognormal distribution, the $25 \%$ data points, the load combination of dead load plus residential live load, and the load ratio of 1.0 be selected for the determination of compressive design value. For Chinese larch dimensional lumber, the compressive design values of grades Ic, IIc, IIIc and IVc of $2 \times 4$ dimensional lumber were $22.9,18.3,14.6$ and $13.8 \mathrm{MPa}$, respectively.

Acknowledgements This project was financially supported by the National Key Technology Support Programs (2017YFC0703501 and 2015BAD14B0502). We are also honored to thank the Processing and Utilization Technology of High Strength Structural Materials team for providing technical support.

\section{References}

1. Zhou HB (2012) Current and future status of wood structure in China (Part I) (in Chinese). China Wood Industry 26(1):7-10

2. Ye KL, Lv JX, Yin YF (2009) R \& D of dimension lumber processing and application in China (in Chinese). China Wood Industry 23(1):4-6

3. Ye KL, Lv JX (2010) Processing and application technology development for larch dimensional lumber (in Chinese). China Wood Industry 24(6):1-3

4. Zhou HB, Ren HQ, Lv JX, Jiang JH, Wang XH (2012) Size effect of length on flexural strength of Chinese fir dimension lumber used in wood structure (in Chinese). J Build Mater 12(4):501-504

5. Zhao X (2010) Study on the strength properties of larch dimension lumber. Dissertation, Chinese Academy of Forestry, Beijing, China

6. Long C, Lv JX, Ren HQ, Jiang JH (2008) Comparison between the Chinese and Canadian visual grading rules for dimensional lumber (in Chinese). China Wood Industry 22(4):23-25

7. Lou WL, Ren HQ, Wang ZH, Zhou HB, Luo XQ, Jiang JH (2013) Grading of structural larch dimension lumber (in Chinese). J Build Mater 16(4):734-738

8. Zhong Y, Sun HL, Lou WL, Ren HQ, Li XZ (2012) Effect of knots on bending modulus of elasticity of larch dimension lumber (in Chinese). J Build Mater 15(4):518-521

9. Zhong Y, Ren HQ, Lou WL (2012) Experimental research on the effects of knot on the bending strength of dimension lumber (in Chinese). J Build Mater 15(6):875-878

10. Jiang JH, Lu JX, Ren HQ, Long C (2012) Effect of growth ring width, pith and visual grade on bending properties of Chinese fir plantation dimension lumber. Eur J Wood Prod 70:119-123

11. Zhou HB, Wang XS (2013) Size effect of bending strength of Chinese larch lumber (in Chinese). J Civ Archit Environ Eng 35(1):117-120 
12. Zhou HB, Jiang JH, Wang XS (2012) Size effects of width on tensile strength of visually-graded Chinese larch lumber (in Chinese). J Beijing For Univ 34(1):127-130

13. Jiang JH, Lu JX, Ren HQ (2012) Study on characteristic values for strength properties of Chinese larch dimension lumber (in Chinese). J Build Mater 15(3):361-365

14. Zhao X, Lu JX, Jiang JH (2009) Study on characteristic values of Chinese larch dimension lumber bending properties (in Chinese). China Wood Industry 23(6):1-4

15. Zhao X, Guan X, Cui YJ, Huang ZH (2013) Probability distribution of ultra compression strength for the dimension lumber of larch (in Chinese). For Sci Technol 38(4):41-44

16. Zhu EC, Niu S, Qiao L, Pan JL (2017) Reliability analysis of wood structures and method for determining design strength value of timber (in Chinese). J Build Struct 38(2):28-36

17. GB 50005-2003 (2003) Code for design of timber structures. China Standards Press: Beijng, China

18. PS 20-14 (2014) Standard grading rules for Canadian lumber. National lumber grades authority, Surrey, BC

19. ASTM D4442-07 (2006) Standard test methods for direct moisture content measurement of wood and wood-base materials. ASTM International: West Conshohocken, USA, PA

20. GB/T 28993-2012 (2012) Standard test methods for mechanical properties of structural lumber. China Standards Press: Beijng, China

21. Barrett JD, Lau W (1991) Compression strength adjustments for moisture content in Douglas-fir structural lumber. Wood Fiber Sci 23(4):543-557
22. NDS-97 (1997) National design specification for wood construction. American Wood Council, USA

23. CSA 086 - 09 (2009) Engineering design in wood. Canadian Standards Association, Canada

24. ASTM D1990-16 (2016) Standard practice for establishing allowable properties for visually-graded dimension lumber from ingrade tests of full-size specimens. ASTM International, West Conshohocken, PA

25. Foschi RO, Folz BR, Yao FZ (1989) Reliability-based design of wood structures. First Folio Printing Corp. Ltd, Vancouver

26. Zhao GF, Jin WL, Gong JX (2000) Reliability theory of structures. China Architecture \& Standards Building Press, Beijng

27. GB 50009 - 2012 (2012) Load code for the design of building structures. China Standards Press, Beijng

28. GB 50068 - 2001 (2001) Unified standard for reliability design of building structures. China Standards Press, Beijng

29. GB $50153-2003$ (2003) Unified standard for reliability design of engineering structures. China Standards Press, Beijng

30. ASTM D2915-03 (2003) Standard practice for evaluating allowable properties for grades of structural lumber. ASTM International, West Conshohocken

31. Zhu EC, Pan JL (2011) Improving technical standards for wood structures with reference to international experience (in Chinese). China Wood Indus 25(3):26-29 